\title{
El espectador en la imagen fotográfica versus el spectator
}

\author{
Nekane Parejo Jiménez \\ Profesora de Comunicación Audiovisual de la Universidad de Málaga
}

\section{Resumen}

La representación fotográfica del espectador tanto dentro como fuera del encuadre de las instantáneas de los atentados de ETA insertas en la prensa española desde finales de la década de los 60 hasta nuestros días atraviesa por diversas etapas. En cada una de éstas se responderá a tres cuestiones: la distancia espacial y temporal a la que se encuentra del lugar de los hechos, los contenidos que ve y cuál es el papel que desempeña.

Palabras clave:

Fotografía, atentados de ETA, el espectador y prensa española.

\section{Abstract}

The spectator photographic representation as much inside as outside the frame of snapshots of ETA attacks inserted in the Spanish press, from the end of the sixties decade to the present time, crosses by diverse stages. In each one of these will respond itself to three questions: the distance in space and temporary to which one is from the place of the facts, the contents that it sees and which is the paper that carries out.

Key words:

Photography, attacks of ETA, the spectator and Spanish press. 


\section{Introducción}

El ojo que tú ves no es ojo porque tú lo veas; es ojo porque te ve. Antonio Machado

Como punto de partida el espectador es el que se sitúa, físicamente o a través de las imágenes de un medio, en el lugar de los hechos, pero sin formar parte de ellos. Se puede decir que su labor se limita a mirar lo ocurrido, autoexcluyéndose deliberadamente de su participación. Según este axioma la noción de espectador y observador estarían estrechamente emparentadas. La función de ambos es observar un "objeto", cuya significación etimológica no es otra que "algo que yace delante” (lat. ob- + -jactus) (Bryson, 1983: 55). Desde esta perspectiva el objeto es lo que es observado por el observador y por el espectador, mientras que el sujeto va más allá, actúa.

Antes de establecer las divergencias entre observador y espectador, se debe señalar que el hecho de que ambos coincidan en la función de observar implica algo más que la acción de mirar únicamente, y de acuerdo con Jonathan Crary esto supone "ser el siervo de unas normas de visión. La observación, es en definitiva, un fenómeno de carácter sociocultural, y el observador, un sujeto inmerso en un sistema discursivo, tecnológico e institucional heterogéneo" ${ }^{1}$. En definitiva, la mirada del observador y el espectador está mediatizada por una serie de convenciones y estereotipos previamente definidos.

Llegados a este punto la cuestión es determinar qué es lo que separa al primero del espectador. Roland Barthes considera que el Spectator, como él lo denomina, "somos los que compulsamos en los periódicos, libros...”. Es decir, el que examina, confronta o coteja lo registrado en la imagen impresa que designa como "Spectrum de la Fotografía porque esta palabra mantiene a través de su raíz una relación con espectáculo” (Barthes,2004:35).Y ese es

1 Crary, Jonathan, Techniques of the Observer. On Vision and Modernity in the Nineteenth Century, October Books, MIT Press, Cambridge, Mass., 1990, p.6. Citado por Gonzáles Flores, Laura, Fotografía y pintura ¿dos medios diferentes?, Gustavo Gili, Barcelona, 2005, p.35. 
el matiz que distingue al espectador, que no es otro que aquel que mira, examina, coteja un espectáculo, mientras que el observador puede centrarse en un objeto sin más.

Cuando Barthes alude a esta figura la circunscribe en exclusiva al ámbito de los medios de comunicación. Nos está hablando de lo que Wolheim denomina como el espectador de la imagen. Sin embargo, este autor diferencia entre "dos tipos de espectadores. Está el espectador de la imagen y está el espectador en la imagen. Ambos se distinguen según dónde estén situados y qué sea lo que vean" (Wolheim, 1987:59). Nos habla por tanto, del espectador de la imagen que es el que está fuera de ella, y al que a partir de ahora siguiendo a Barthes denominaremos spectator. Es el que ve, pero no es visto. Y del espectador en la imagen que es el que es captado por los márgenes del encuadre.

A la luz de los planteamientos puestos de relieve anteriormente, vamos a considerar estas figuras a través de las fotografías de prensa en relación a los atentados de ETA². La extensión del periodo abarcado en este estudio, desde la década de los 60 hasta nuestros días, conlleva una evolución en la pasividad asignada como rol al espectador, que propiciará que tengan cabida acciones de diversa índole no contempladas en los supuestos iniciales.

Aquí, sin omitir al espectador de la imagen, que como se verá es el que marca las pautas de representación fotográfica a partir de los 90, nos centraremos inicialmente en el espectador en el encuadre en las dos vertientes mencionadas.

La línea divisoria entre el espectador pasivo y el activo se estudiará mediante las tomas fotográficas que dan cobertura informativa a los atentados de ETA y que situará en el encuadre a un mismo espectador que con el transcurso de los años ya no estará interesado en perpetuarse junto al hecho en sí, el atentado, sino que tomará parte activa alineándose como protagonista de unas instantáneas más emparentadas con las consecuencias del suceso que con éste.

Este planteamiento nos lleva a establecer la existencia de dos tipologías: la de aquel cuya presencia es un mero acompañamiento y la del que se sitúa en la instantánea por méritos propios.

2 He tratado este tema en Parejo Jiménez, Nekane, Fotografía y muerte: representación gráfica de los atentados de ETA (1968-1997), Bilbao, UPV, 2004. 
Será esta premisa la que permita afirmar, conforme a lo expuesto por Jonathan Crary, que la representación de la figura del espectador va a acusar una serie de transformaciones que corren paralelas no sólo a las necesidades del reportero, sino a las circunstancias histórico y sociopolíticas que han ido instaurándose en la sociedad española.

Las diferencias entre los distintos estadios que concurren en el periodo abarcado se acometerán mediante el estudio de las fotografías publicadas en la prensa española. En concreto, las de los diarios El Correo, Hierro y La Gaceta del Norte. A los que, con la llegada de la democracia, se añadirán los regionales Deia y Egin y El País de ámbito nacional.

Las diversas fases por las que discurre el espectador se precisan a través de tres cuestiones: la distancia espacial y temporal a la que se encuentra del lugar de los hechos, los contenidos a los que tiene acceso en relación al que está fuera del encuadre y el nivel de protagonismo dentro de la toma (papel que desempeña). En definitiva, qué espacio ocupa el espectador, qué es lo que ve y cuál es el rol que representa.

\section{La ausencia}

La primera víctima de un atentado de ETA, la niña de dieciocho meses Begoña Urroz Ibarrola, muere a causa de un artefacto explosivo en julio de 1960 en San Sebastián. La cobertura informativa de este hecho se limita a quince líneas a una columna en el periódico El Correo sin ninguna fotografía que ilustre el suceso.

Un esquema similar, donde la ausencia de imágenes es palpable, se reproduce años después en junio de 1968 con la muerte del Guardia Civil de Tráfico José Pardines Arcaiz, segunda víctima de la banda terrorista.

Será el asesinato de Melitón Manzanas el 2 de agosto de 1968 el que marque el punto de inflexión bajo el que aparecen las primeras fotografías en prensa. En cualquier caso se trata de instantáneas caracterizadas por su escasa calidad y una reducida vinculación con el hecho propiamente dicho. La publicación de una toma del lugar donde se supone se encontraba escondido el asesino junto a la foto carné y una instantánea con la casa de la víctima son 
editadas por diversos periódicos a distintos tamaños. El documento gráfico se completará al día siguiente con las fotografías del funeral.

Este tema, las exequias, se convertirán en el objetivo prioritario de los fotógrafos que conocen sobradamente las reglas de la censura y saben que sus imágenes de este acto no serán prohibidas, siempre y cuando se atengan a una serie de estereotipos que han formado y formarán parte del imaginario de cualquier funeral. Véanse los compañeros portando el féretro o la multitud de personas que acompaña al fallecido, Fermín Monasterio, ante la Parroquia de San Pedro de Deusto en Bilbao.

Ante esta situación de precariedad informativa cabría señalar que en la década de los 60 el espectador no dispone de un espacio propio en el lugar de los hechos. No tiene cabida en el lugar del atentado, es un espectador ausente. Si en ese momento los diarios se limitan a reproducir escasas tomas y alejadas en el tiempo al instante de la muerte, difícilmente podrán verse a personas contemplando los hechos o sus consecuencias.

No obstante, sí es registrado en los funerales. Es un espectador distante, al que sólo se le muestra un acto protocolario. Estamos ante unas fotografías en las que la amplia distancia narrativa implica que el número de elementos en la imagen sea tan elevado que apenas sí se aprecia su figura. Esta circunstancia conlleva a que el spectator no otorgue importancia a esta figura, si no es en cuanto a su cantidad.

Cuando el spectator se enfrenta a las imágenes el día después del atentado se encuentra desorientado debido a que la relación del material fotográfico con el suceso es tan exigua que difícilmente puede averiguar de qué se trata. Las imágenes no son más que un dudoso acompañante del texto. El spectator tiene que moverse en el terreno de la intuición, más que en el de la visión. Una flecha inserta en una toma puede ponerle sobre aviso del algún tipo de incidente, que no tiene porqué concretarse en un atentado. Sin embargo, el número de interrogantes que emergen al leer el titular del hecho como el medio empleado en el atentado, si ha habido víctimas o no... no son resueltos en ningún caso por las instantáneas que los editores de los años 60 publican. En este sentido John Berger afirma que "todos los acon- 
tecimientos fotografiados son ambiguos, excepto aquello cuya personal relación con el hecho es tal que su propia vida suple la continuidad perdida" (1982:128).

El problema es que en estas imágenes la ambigüedad ha sido reemplazada por la ausencia y es el spectator quien tiene que imaginar a ese hombre del que se le presenta su foto carné víctima de un atentado o que las escaleras recogidas en una instantánea son las que llevan al escenario del suceso.

\section{Anonimato y distancia}

Hasta después de la muerte de Franco, en concreto hasta 1976, se mantendrá este patrón de representación. Sin embargo, si los parámetros empleados permanecen en lo que a las exequias se refiere, se observa como, con el transcurso del tiempo y de forma progresiva, el lugar de los hechos hasta ahora exento de vida va poblándose. Periodistas, personal sanitario, bomberos, familiares de la víctima, autoridades... se personan en el lugar del atentado y forman parte de los encuadres que edita la prensa.

Este incremento en la visualización de personas no debe desviar nuestra atención de la figura que aquí estamos tratando, dado que todas las que son captadas por los objetivos de los fotógrafos tienen un motivo en común, están vinculadas de una u otra manera con el suceso. Las conexiones son diversas, algunos se encuentran allí debido a su trabajo, otros ejercen labores de representación y otras vinculaciones que se pueden situar en el terreno sentimental. En cualquier caso no estamos ante personas ajenas al hecho cuyo cometido es mirar, cuya misión es ocupar un espacio para ver en directo lo ocurrido.

La Gaceta del Norte del 10 de junio de 1976 publicará la primera fotografía en la que el espectador dentro de la imagen se hace visible y protagonista en el lugar de los hechos. En ella varias personas anónimas se constituyen en el motivo principal. La acción de mirar se subdivide en dos campos, las que dirigen sus ojos hacia una circunstancia ajena al encuadre fotográfico y la que mira hacia el suelo, hacia el charco de sangre de la víctima, Carlos Albo. Y aunque la sangre es imperceptible debido a la escasa calidad de la imagen, el pie de foto se hace eco de esta situación y se puede apreciar una clara actitud de voyeurismo en los retratados. 
En idéntica actitud se registra a los congregados en semicírculo junto a una fachada en la que nuevamente mediante el texto se informa al lector de lo que están observando los espectadores. Son los impactos de bala y el reguero de sangre producidos por el asesinato del sargento Francisco Martínez González recogidos en una imagen publicada por El Correo y Egin el 28 de mayo de 1978.

Ambos casos coinciden en mostrar la figura del espectador con una distancia narrativa menor con respecto al fotógrafo. Sin embargo, las imágenes por si solas no nos dan la pauta de lo que están mirando, ni el trecho que les separa de su referencia visual.

Será con motivo del asesinato de Anselmo Durán cuando el espectador y el charco de sangre se perciban en el mismo encuadre. En una foto de Egin del 10 de octubre de 1978 se visualizará en primer plano junto a unas escaleras los restos de sangre de la víctima. Al fondo, y manteniendo cierta distancia también queda inmortalizada la hilera de personas que contempla los vestigios de lo que allí sucedió.

Se deben destacar dos aspectos, el primero que los presentes parecen más interesados en el instante de la toma fotográfica por el objetivo de la cámara o por la conversación, que por los rastros del atentado. En segundo lugar, y si ampliamos el abanico de fotografías editadas ese día, se constata que los contenidos que ve el espectador en la imagen son los mismos que los que aprecia el que está fuera de ella. No existen tomas de un tiempo anterior en las que el spectator tenga acceso al cuerpo del asesinado. Todos contemplan lo mismo, el charco de sangre. De aquí se deduce que el fotógrafo y el espectador han llegado tarde al lugar de los hechos.

A partir de 1978 se hace cotidiana la imagen del fallecido in situ, pero no se puede olvidar que la primera toma de una víctima, el taxista Manuel Albizu, en el lugar en el que le dispararon, fue publicada en la portada de La Gaceta del Norte el 16 de marzo de 1976, y no tuvo continuidad. Habrá que esperar hasta el otoño de 1977 para que el spectator pueda ver una fotografía de contenidos similares. Será Egin el 9 de octubre quién editará dos fotos de los cuerpos sin vida de los guardias civiles que escoltaban al presidente de la Diputación Provincial de Vizcaya, Augusto Unceta: Antonio Hernández Fernández y Ángel Rivera Navarro. Poco después, el 29 de noviembre de 1977 El País y Deia insertan una imagen en la que el protago- 
nista es el cadáver del comandante Joaquín Imaz tumbado en una carretera junto a la rueda de un automóvil. Esta lenta cadencia a la hora de estampar fotografías que muestren a la víctima del atentado, tal y como quedó tras sufrirlo, encuentra su justificación inicialmente en la censura franquista, tal y como se ha expuesto. No obstante, tras la muerte de Franco en 1975 y con una incipiente democracia, se constata que durante al menos dos años el spectator a penas si tiene acceso a imágenes de este tipo. Las causas cabría buscarlas en dos direcciones.

Por un lado, la falta de infraestructuras para cubrir el elevado número de atentados. El periodista Arcadi Espada se expresa contundentemente refiriéndose a esta época "En el País Vasco parecía haber más terroristas que periodistas" (2000:16).

Y por otro, en las inercias en los modos de trabajo adquiridas en el pasado que perviven sobre todo en diarios tradicionales como La Gaceta del Norte, Hierro y El Correo que optan por instantáneas que devuelvan al spectator una imagen de la víctima más acorde y más próxima a la vida que a la muerte. Fotografías que parecen inspiradas en las apreciaciones de Estrella de Diego respecto a las tomas de muertos: "presentan esos cuerpos como probables y enteros, vestidos de personajes para la narración, como aquellos que aún permanecen, al menos en ese espacio donde todo es posible, donde sólo es posible- el virtual de la fotografía" (1996:38). Y así encuentran su espacio en las páginas de los periódicos, durante un tiempo que se prolonga, fotos del pasado del fallecido o perfectamente ataviado en el féretro. Tomas que no desean exhibir cuerpos marcados por evidentes signos de violencia, ya que cuando esta se explicita es mediante símbolos que en ningún caso aúnan, todavía, al espectador con el cadáver de la víctima, sino con algún indicio de su muerte. Esto sitúa al espectador y al spectator en el terreno de la especulación acerca de lo sucedido.

Retomando la figura del espectador en el encuadre, se debe hacer mención de otro lugar común de los espectadores expuestos hasta el momento, y que va a cambiar de forma más notoria a partir de 1979, es el estatismo. Todos ellos parecen tener un espacio desde el que mirar delimitado y establecido, aunque de forma aparentemente voluntaria.

Dentro de este marco de inmovilidad, anonimato y distanciamiento se puede establecer una nueva tipología que entronca perfectamente con una segunda subdivisión que realiza Woll- 
heim. Inicialmente decíamos que este autor escindía en dos arquetipos al espectador, el que está fuera y el que se coloca en el interior de la imagen. A partir de este último nos define dos nuevos modelos: el interno representado, que es al que se ha hecho referencia hasta ahora, $\mathrm{y}$ él no representado al que coloca en la frontera entre la imagen y la realidad "tiene que estar situado en el espacio representado de tal manera que pueda ver todo lo que la pintura representa y que lo pueda ver tal y como lo representa. Ve cara a cara lo que ve el espectador del cuadro en su superficie" (1987:59).

Estamos ante un personaje que se encuentra en el espacio y en el tiempo en el que transcurren los hechos. Sin embargo, no cobra presencia en la imagen ya que ve lo mismo que el spectator y tiene como misión que se produzca una identificación de este con él para lograr facilitarle la asimilación de los contenidos representados. Bajo este prisma podemos convenir que Whollheim parece referirse a la figura del fotógrafo, siempre que maticemos que se trata del fotógrafo en el instante que aprieta el disparador, pues es únicamente en ese lapso en el que puede ver lo mismo que verá el spectator. Aunque esta afirmación nos llevaría a interminables debates al respecto.

En las fotografías que se están exponiendo el patrón más cercano a la figura del espectador no representado es aquel que tiene numerosas concomitancias con algunas pinturas de Caspar David Friedrich como Acantilados de Rügen o Dos hombres junto al mar a la salida de la luna. El primer término de éstas se encuentra ocupado por la Rückenfigur que es un personaje de espaldas al artista que observa el paisaje y que se ubica en una posición que le permite cumplir las dos funciones que justifican su presencia, guiar la mirada del spectator hacia el interior del cuadro y lograr el campo visual más extenso posible, siempre teniendo en cuenta que el espacio visual del spectator es mayor que el de la Rückenfigur.

La primera fotografía, publicada por El Correo el 24 de octubre de 1978, y que responde a estas características en el ámbito que se está estudiando muestra el lugar donde fueron asesinados los guardias civiles Luciano Mata Corral y Luis Carlos Cancedo. En ella un individuo solo y de espaldas a la cámara sirve de guía hacia una serie de inserciones numéricas que pretenden reconstruir narrativamente el atentado. 
En otras ocasiones el fotógrafo opta por la fragmentación del cuerpo del voyeur y sólo incorpora deliberadamente una parte de éste, habitualmente sus pies, al encuadre como medio para orientar la mirada del spectator hacia el motivo principal. El 11 de marzo de 1978 La Gaceta del Norte reproduce una toma de un detalle de la calle en la que fue asesinado José María Acedo en cuyo primer plano se intuyen difusamente unas manchas que supuestamente son restos de sangre de la víctima. Al fondo varios pares de pies se encaminan hacia este motivo principal y consiguen darle el protagonismo suficiente para que el spectator no se encuentre ante una fotografía abstracta.

Esta fórmula metonímica que sustituye una parte por el voyeur completo sirve para potenciar, aún más si cabe, el anonimato que da título a este epígrafe. Al igual que en el caso de la Rückenfigur y que las representaciones distantes y difusas, aquí presentadas, anulan la posibilidad de contemplar los rostros de los espectadores y lo que es más relevante lo que éstos transmiten.

\section{El espectador próximo y activo}

El 30 de diciembre de 1978 es asesinado el taxista Eduardo Sampil Belmonte en el interior de su automóvil. El Correo y La Gaceta del Norte incorporan una toma en la que el espectador en el encuadre es visible, aunque con puntos de vista absolutamente distintos. En el primero se recoge una perspectiva en la que el coche se sitúa frente a la cámara con una evidente desproporción de la parte delantera, posiblemente debido al uso de un objetivo de distancia focal corta que permite al fotógrafo introducir en el encuadre a varias personas que miran a través de las ventanillas laterales.

La toma de La Gaceta del Norte centra su interés en la víctima que aparece en primer término con una manta que cubre su rostro sentado en el interior de su vehículo. No obstante, al fondo, también hay sitio para unos espectadores que, aunque no intervienen, se acercan al cadáver, de momento, cubierto.

En esta línea donde se produce una aproximación al asesinado por parte del voyeur en el encuadre y se quiebran las rígidas y simétricas atalayas que servían al mirón para otear el 
atentado en la distancia, se localiza una fotografía en la que el público se concentra entorno a la puerta de las dependencias de la Policía Municipal de Pasajes Ancho mientras curiosea la ambulancia que trasladará el cuerpo sin vida de Juan Jiménez Gómez.

Los tres casos expuestos forman parte de un elenco de fotografías en las que desaparece el espectador representado ordenadamente en un punto determinado para ser sustituido por otro más próximo, que parece abalanzarse sobre un cadáver todavía no visible. Sin embargo, la integración y contigüidad entre el espectador y el fallecido es patente.

Este nuevo arquetipo en la representación puede venir motivado por tres situaciones: el hecho de que el espectador se persona antes en el lugar del atentado porque tiene conocimiento de él antes que en otras épocas, que no existen barreras que corten el paso a este acercamiento y a su vez el miedo a aproximarse es menor. Por último, el espectador no se avergüenza de mostrar en público el morbo que le producen este tipo de sucesos.

Estas circunstancias conllevan a que el spectator, el espectador y el fotógrafo se han instalado en un círculo en el cual este último, si desea estar a la altura de lo que solicita el primero, debe ofertar cada vez tomas más impresionantes. Instantáneas, que van copando las páginas de los diarios y, que son limítrofes con el tiempo del atentado y que hacen que el espectador en el encuadre, al que se le está acostumbrando a acortar distancias cuando está fuera de él, se aproxime también cuando lo constituye. Debe señalarse que estas condiciones de mostración son coyunturales y que pasarán a otros estadios más colindantes aún si cabe y que culminarán con la inserción del cordón policial, que nuevamente separará al espectador del suceso en cuestión.

\section{Personalización y diversificación del espectador}

El bienio 79-80 se caracteriza por la repetición de arquetipos de representación utilizados en todos los periodos anteriores dando lugar a una diversificación de esta figura. Se alternan fotografías en las que predomina el concepto de masa junto a otras en las que la soledad se hace patente. El único aspecto novedoso reseñable es la publicación de una fotografía el 3 de enero de 1979 en Deia con motivo del asesinato de José Mª Herrera Hernández en la que se aprecia 
por primera vez frente a la cámara a un espectador en solitario. Su fuerza radica no sólo en la ausencia de otras personas en primer plano, sino en su ubicación a la izquierda del encuadre dejando para la parte central los restos de sangre derramados sobre un bordillo. Anteriormente, El Correo había publicado una instantánea el 24 de octubre de 1978 de un solo espectador, sin embargo se encontraba de espaldas al objetivo del fotógrafo.

Respecto a las acciones desempeñadas, comparten las páginas de los diarios individuos estáticos que miran, con otros que hacen de guía para el spectator, o caminan a la vez que observan o indican impactos de bala o se asoman al interior de un vehículo a través de sus ventanillas como la imagen que insertan varios diarios, el 1 de noviembre de 1979, en la que varias personas curiosean el coche que se disponía a poner en marcha Manuel Fuentes Fontán cuando le dispararon.

Las muestras cuya función es conducir la mirada hacia lo retratado son escasas, pero no por ello insignificantes. El 4 de enero de 1979 La Gaceta del Norte edita una toma del lugar donde fue asesinado Constantino Ortín Gil en la que se registra a varias personas de espaldas. Un día antes, el 3 de enero de 1979, Deia había impreso una instantánea en la que el margen izquierdo muestra en primer plano la mitad de la espalda de un guardia que nos encauza para contemplar las secuelas de la explosión que mató al artificiero Francisco Berlanga Robles.

Dentro de este apartado de las acciones, se debe reseñar la aparición de un modelo de representación que aúna varias tipologías de voyeurs. Se encuentra una muestra en una imagen que da cobertura a la información sobre el atentado a Juan Luis Aguirreurreta Arzamendi, el 17 de noviembre de 1979, publicada por Deia donde se aprecia un individuo que se detiene, para observar el lugar de los hechos junto a otro que sigue su recorrido mientras contempla lo ocurrido.

Otro aspecto a tener en cuenta son los contenidos a los que dirige su mirada el espectador de finales de esta década que no son otros que los expuestos hasta el momento, y que se distribuyen en cuatro grandes bloques de menor a mayor profusión: los que no perciben nada, los que observan el instante en que la víctima es introducida en una ambulancia, los que 
orientan sus ojos hacia los restos todavía presentes en el escenario del crimen y los que intentan escrutar bajo la sábana o manta que cubre el cuerpo sin vida del fallecido.

El grado de información que obtiene el mirón acerca del suceso es directamente proporcional a dos factores: la rapidez con la que se sitúe en el lugar de los hechos y el tiempo que se demore el levantamiento del cadáver. En algunos casos, cuando se produce una dilación en la llegada y el cuerpo sin vida es trasladado con celeridad, el espectador no ve nada y el spectator tiene que recurrir al pie de foto para comprender que hace allí. Este es el caso de una toma que edita Deia, el 30 de marzo de 1980, fecha en la que fue asesinado el niño José Ma Piris, y en la que sólo se aprecia gente subida en una barandilla. El spectator tomará conciencia de que se trata de "el lugar en que estuvo aparcado el coche del guardia civil y donde quedó el artefacto, que luego estallaría” mediante este texto escrito en pasado.

En otras ocasiones el voyeur llega a tiempo para observar como el cuerpo sin vida de la víctima es introducido en la ambulancia, como en la fotografía de Egin del 4 de enero de 1979 en la que se retrata al gobernador civil de Madrid, Constantino Ortín Gil en ese preciso instante. Incluso a veces coincide en el encuadre con el cadáver cubierto, como ya se vio en el precedente que estableció la toma de Eduardo Sampil y que ahora reitera este mismo diario el 29 de abril de 1979 con otra víctima, Pedro Ruiz Rodríguez, cuyo cuerpo se encuentra en el suelo tapado por una sábana entre una camilla y la ambulancia en el cruce donde fue asesinado.

Es indiscutible que se ha producido una aproximación en el tiempo y que el fotógrafo llega antes al lugar de los hechos para poder captar escenas en las que el cadáver se encuentra a la espera de su levantamiento o espectadores y camilleros, retirando el cuerpo sin vida del fallecido, constituyen encuadres más cercanos al instante de la muerte. Como señala Luis Fernández Galiano: "El espectador se ha convertido en un auténtico voyeur. Nada debe estar oculto, todo debe estar disponible”3.

\footnotetext{
3 Conferencia de Luis Fernández Galiano (arquitecto y director de la revista Arquitectura Viva Universidad Politécnica de
} Madrid) ofrecida en los II Encuentros de Arte y Cultura bajo el título de Semiótica y Museo: El laberinto de la mirada. 
No obstante, si como se ha expuesto el spectator tiene acceso al cadáver in situ, no será hasta la década de los 80 cuando coincidan en una misma fotografía el espectador y el cadáver del asesinado tal y como murió.

Otro aspecto a reseñar es la nueva tipología dentro de la fragmentación que se reproduce. Anteriormente, se señaló un modelo según el cuál la fotografía sólo registraba una parte del cuerpo, frecuentemente los pies. Ahora el planteamiento difiere, y más que ante una fragmentación propiamente dicha, estamos ante un corte en el encuadre que secciona a los espectadores por la parte superior de su figura dependiendo de su altura. De este modo, con la cabeza cortada, plasma El País el 4 de septiembre de 1980 en portada a los voyeurs que miran la sábana que cubre el cuerpo de Antonio Fernández Guzmán.

Este prototipo compositivo cuya profusión en las páginas de los diarios se hará más notorio más adelante, encuentra su justificación en el hecho de preservar la identidad de algunos profesionales como son los guardias civiles y los policías que mediante este patrón se mantienen en el anonimato sin necesidad de colocar las habituales bandas negras sobre sus ojos. Ya el 29 de julio de 1979 Deia editó una fotografía en la que a los protagonistas, tres niños apoyados en la esquina de una pared, se sumaba un policía del que sólo se apreciaba la mitad de su cuerpo en el que destacaba su arma en su mano derecha. El Correo y El País también insertan la figura del espectador seccionada en la cobertura de este atentado, en el que fallecieron Miguel Ángel Saro y Emilio López. El primero reproduce en un plano muy próximo a uno de los espectadores escindido verticalmente, mientras detrás se coloca un segundo que posa. La portada de El País, por su parte, muestra a tres hombres, uno de ellos el más cercano a la cámara cercenado, señalando los impactos de bala y los rastros de sangre de una puerta.

Mención a parte requieren los espectadores, que podíamos denominar de segunda fila, que también se captan en las fotografías de este bienio. Nos referimos, por ejemplo, a aquellas tomas en las que para lograr un reportaje más completo el periodista se ha desplazado a la ciudad en la que nació la víctima. Su acción, dado que no estamos en el lugar de los hechos, ni en el entierro, se limita a merodear alrededor de la vivienda de la víctima y contemplar el gesto apenado de los familiares de ésta. Una instantánea del 16 de mayo de 1980 recogida en El Co- 
rreo con motivo del fallecimiento de tres policías nacionales en San Sebastián se sitúa en Almería, ciudad de donde era uno de ellos, y da cuenta de este nuevo arquetipo en la representación del espectador.

\section{Espectador, spectator y la víctima in situ}

Hasta la década de los 80, en concreto hasta 1981, no existe constancia gráfica que reuniese al voyeur y al cadáver en el mismo encuadre, aunque algunas muestras nos proporcionan las pistas suficientes para saber que ambos compartían el mismo espacio. Es ahora cuando se manifiestan los primeros paradigmas en los que el espectador y el cuerpo sin vida in situ convergen en una misma instantánea, mientras que el spectator tiene un amplio conocimiento de ambos a través de las páginas de todos los periódicos objeto de estudio. A continuación, se enumeran tres fotografías de tres diarios diferentes en orden creciente en lo que a cercanía se refiere con respecto al instante del atentado.

La primera, fechada el 31 de mayo de 1985, reproduce a varios individuos recogiendo el cadáver del adolescente Alfredo Aguirre en primer término. Tras ellos, Deia plasma la figura seccionada por la cintura de varios observadores.

Años antes, el 11 de julio de 1981, El Correo había registrado un momento anterior en dos fotografías con público. En una, dos personas de espaldas prestan atención a los movimientos del juez junto al asesinado Joaquín Garjón González y en la otra la gente le contempla desde una marquesina situada a cierta distancia. Mientras el pie de foto se hace eco de la presencia de los espectadores y el fallecido: “Todavía no había sido retirado el cuerpo de Joaquín Garjón del andén de la estación de Basauri. Otros, viajeros, desde la marquesina observan la escena”.

Por último, el cuerpo sin vida de Luis Reina Mesonero tumbado en el portal de su casa es observado por algunos espectadores que se encuentran de espaldas a la cámara en la instantánea que inserta el periódico Egin, el 14 de septiembre de 1989.

El modelo de representación que patentizan estas muestras, entre otras, cuyos contenidos son muy similares consolidan un imaginario común en el que se produce el mayor acercamiento entre 
la figura del espectador y el final de la vida de los asesinados. La trascendencia del cadáver in situ en este periodo marca las fórmulas representativas que se asignan al voyeur que coinciden en la ocupación de un plano secundario en la escena. Ahora bien, los medios para conseguir esta ubicación pueden ser tres y todos ellos pasan por un retorno al anonimato: sin que la cabeza forme parte del encuadre, en la lontananza o retratándole de espaldas a la cámara.

En cualquier caso, no debe confundirse este patrón, cuyo fundamento es pasar desapercibido, con el del espectador anónimo de los 70 que nunca aparece junto al cadáver en el lugar de los hechos tal y como cayó. Ahora, cuando la instantánea no capta el cuerpo inerte sin tapar la figura del espectador ocupa una posición frontal, visible y reconocible, reproduciendo esquemas anteriores cuyos contenidos son conocidos por el spectator como son el charco de sangre, entre otros rastros del suceso, el cadáver tapado o en el instante de introducirlo en la ambulancia y a veces, nuevamente, nada. No obstante, como se expuso en el comienzo de este apartado, el rasgo más significativo de esta década es el hecho de haber conseguido mostrar en la misma fotografía: el cadáver de la víctima y al espectador porque esto supone que el espectador y el spectator vuelven a ver idénticos contenidos.

Otro aspecto característico, es que paralelamente al declive de la figura del testigo en el imaginario de la representación de los atentados de ETA se produce un incremento en el número de espectadores que contemplan las consecuencias de éstos. Con motivo del asesinato de Luis Cadarso San Juan el pie de foto del 14 de abril de 1981 es explicito en esta cuestión: "Si bien no hubo testigos del atentado, muchos curiosos presenciaron el momento en el que el cuerpo de la víctima era introducido en una ambulancia de DYA".

Por último, se debe mencionar que, aunque la función del espectador es meramente contemplativa, y por tanto, exenta de acciones, el reportero intenta acercarse al público cuando excepcionalmente éste manifiesta alguna reacción ante el suceso. Esta perspectiva absolutamente novedosa y que le otorga protagonismo está vinculada al género fotográfico de sucesos, a través de uno de sus máximos exponentes, Weegee, que en palabras de Patricia Bosworth refiriéndose a las tomas de éste señalaba: "A pesar de que muchas estaban tomadas a una discreta distancia de los cadáveres, Weegee siempre captaba las expresiones de horror en los rostros de los espectadores del suceso" (1999: 296). 


\section{El spectator se cuela en el encuadre}

Con los 90 se produce un cambio que gráficamente se traduce en una cobertura informativa cuyo máximo exponente es la parquedad. Ni las motivaciones, ni las fórmulas representativas de esta vuelta a la sobriedad pueden equipararse con estadios anteriores. A finales de los 60 y principios de los 70 la escasez de imágenes y de elementos significativos en estas imágenes, como ya se ha expresado, se supeditaban a la situación política imperante y a las condiciones técnicas del momento. Ahora, después de largos años, entorno a quince, mostrando sin mesura fotografías desgarradoras, cuya única cortapisa fue una falta de infraestructura inicial, emergen los primeros signos de una autocensura por parte de algunos fotógrafos que se expandirá paulatinamente a todos los diarios. El periodista especializado de ABC, Javier Pagola, sitúa el punto de inflexión a finales de los 80 "hasta más o menos el año 1987, hasta esa fecha más que víctimas, había muertos, reflejados en fotos tremendas. Muertos por disparos a bocajarro, con la cara desencajada. No había pudor a la hora de publicar esas fotos" (2003:65).

Hasta los 90, el espectador dentro y fuera del encuadre siente deseos de mirar y en su fuero interno anhela compartir con el fallecido la ilusión de estar presente en ese momento final en el que ve, pero no es visto. No es visto el spectator cuando ojea las páginas de los diarios y tampoco la víctima puede ver al espectador en el encuadre. Con el tiempo la mirada de ambos se torna inconveniente y una expresión popular ya poco empleada, y que reprobaba la mirada insistente del otro, cobra fuerza a modo de interrogante “ $i$ Quieres mi foto?”. Y tanto uno como otro responden negativamente. El voyeur en la toma ya no puede ni quiere estar en primera línea del lugar del suceso y el spectator demanda otro tipo de fotografías.

Esta transformación en los modelos de representación fotográfica se va a producir escalonadamente. Durante los primeros años sólo se materializa en buenos propósitos focalizados en no enseñar, que cohabitan con instantáneas cuyo tratamiento registra idénticos parámetros que las de la década pasada y en las que la función del espectador sigue localizándose en el interior del encuadre mayoritariamente. El Correo del 20 de febrero de 1992 con motivo del asesinato de tres civiles en Santander publica en portada una imagen 
que recoge a dos de las víctimas tendidas en el suelo, a las que se suman una ambulancia y diversos espectadores. Entre los que resalta uno que se echa las manos a la cabeza mientras camina.

Las formas de autocensura se concretan en dos vertientes: la desaparición del cadáver como centro de interés de la foto o en su defecto, la mostración de éste más tenuemente. En el primer caso serán la figura del herido, el coche utilizado como arma o una persona indicando el lugar de los hechos, habitualmente un policía, los que reemplacen al cadáver. Por su parte, el carácter sutil en cuanto a lo que se retrata se logra a través de diversos sistemas que pasan por aumentar la distancia narrativa, aumentar la borrosidad, o colocar trabas visuales entre el fallecido y la cámara para en última instancia conseguir que el cadáver se registre escondido o semiescondido tras ellas. Otra posibilidad es la vuelta al retrato del cuerpo sin vida tapado.

Ni en las fórmulas que se emplean para sustituir el cadáver, ni en los mecanismos que refuerzan una visión más etérea de éste, tiene cabida el espectador en el encuadre que con el paso del tiempo y mediatizado por el cordón policial va a eclipsarse como integrante de las fotografías que ilustran la cobertura informativa de los atentados en el lugar de los hechos.

El cordón policial no es un elemento novedoso, y aunque anteriormente de manera muy esporádica se tiene constancia gráfica de él, será en los noventa cuando se le otorgue todo el protagonismo. Su evolución en cuanto a su ubicación en el encuadre muestra una clara inclinación que evidencia que el área acordonada cada vez es más amplia. Esto implica un alejamiento del espectador.

En los primeros años sólo se le reproduce en el último termino de la instantánea con un ángulo de toma que certifica de la presencia del reportero gráfico en la zona de acción. Sin embargo, los espectadores siempre están detrás. Este es el caso de la fotografía de Egin con motivo del asesinato de Fabián Moreno, el 8 de noviembre de 1991, en la que por estricto orden de planos se observa primero el vehículo destrozado del guardia civil, detrás el cordón policial y al fondo las personas que contemplan el automóvil. Esta organización del encuadre se convierte en un prototipo habitual cuya muestra más ilustrativa la publicará El Correo, el 26 de febrero de 1992, para cubrir el atentado de José San Martín Bretón. En ella se ve nítida- 
mente como una cinta divide el espacio del fallecido, cuyo cadáver está siendo examinado, y el del voyeur que mira esta acción.

La única variación compositiva estriba en que con los años el cordón pasa de registrarse al fondo a ocupar un lugar en primer término debido a que el reportero sale de lo que denominabamos zona de acción para colocarse tras éste. Este cambio le obliga a variar el punto de vista y en ocasiones capta dos hileras de la cinta divisoria en cuestión y en otras el primer término está ocupado por alguien que observa lo que ocurre tras el dispositivo. El Correo y Deia publican una fotografía en la que varias personas contemplan de espaldas, tras una cinta con el texto no pasar, el cuerpo sin vida de Pedro Carbonero Fernández el 20 de noviembre de 1991.

Esta nueva fórmula de registro y el incremento en la extensión de la zona acordonada conlleva a que a partir de 1993 se combinen tres modelos de representación del espectador que se traducen en la ausencia de éste, que se le registre de espaldas o sin definición debido a la distancia que le separa del primer término de la toma.

La frecuencia y repercusión en el empleo de este mecanismo hace que los pies de las fotografías le mencionen sin más, como en El Correo del 20 de enero de 1993: "Efectivos policiales acordonaron la zona tras el atentado a Santamaría en la sociedad..." o hagan referencia a lo férreo que fue el control a través del cordón como indica el diario Egin del 21 de enero de 1993: "La policía acordonó rígidamente la calle 31 de agosto".

Tras esta contextualización, se puede afirmar que mientras la distancia temporal del espectador en relación al momento en el que se produce el atentado se reduce. Es decir, que es capaz de llegar cada vez antes y aproximarse más al instante en el que el suceso ocurrió, la distancia espacial aumenta. La separación que media entre el cuerpo sin vida de la víctima, que ahora se intenta que de algún modo pase desapercibido como se ha expuesto anteriormente, y el voyeur, se acrecienta hasta dejarle fuera del ángulo de toma.

En cuanto a los contenidos que visualizan el espectador en el encuadre y el spectator podemos decir que esté último, a pesar de la autocensura, tiene acceso a un volumen mayor de accio- 
nes y a través de los teleobjetivos de los reporteros logra una proximidad de la que carece el espectador en el encuadre que se tiene que conformar con la distancia impuesta por el cordón policial.

Paralelamente a la disminución del protagonismo del espectador en el encuadre de las tomas en el escenario del atentado, se produce un auge de la figura del spectator que por un lado, es en quién están puestas las miradas para decidir los contenidos de las fotografías de esta nueva etapa de autocensura y por otro, porque se constituye en un personaje anónimo cuyo número es cada vez más numeroso ante el hartazgo provocado por los atentados de ETA que se lanza a las calles a manifestarse. Sus actos de repulsa, registrados por los fotógrafos, van a dar cuenta de cómo el spectator, siempre fuera del encuadre; aquel que según Roland Barthes asumía como misión casi en exclusiva la de cotejar la información ahora, aún sin dejar de lado esta labor, es capaz de situarse al otro lado del objetivo y formar parte de la instantánea.

La importancia del spectator es indiscutible si se tienen en cuenta las referencias que los profesionales de los medios hacen al respecto. Valentín Villagrasa, director de Informativos de Televisón Española en San Cugat señala en las Jornadas organizadas por el Consejo Audiovisual de Cataluña en diciembre de 2000 sobre el tratamiento informativo de las tragedias y las víctimas que "La sociedad es receptiva a la morbosidad, la muerte vende (...) Estamos provocando que la gente que podría estar trabajando para ayudar a las víctimas se dedique a filmar porque saben que lo van a vender a la tele".

En cambio, J. Ignacio Fernández, que trabajó como fotógrafo de prensa en El Correo y en la actualidad continua su labor informativa como editor jefe de fotografía de este mismo diario, hace mención del retraimiento que se produce al decidir qué es lo que se debe mostrar y señala que "La autocensura se produce por razones de mercado. El hecho de que los lectores sean reacios a imágenes muy duras es un factor fundamental para que la presencia de fotos violentas sea menor. Sobre todo si las víctimas son cercanas".

El rol del spectator resulta imprescindible por partida doble. No sólo considera inoportuno constatar sobre el papel de periódico la violencia de la muerte, y se le tiene en cuenta buscando nuevas fórmulas, sino que además se sensibiliza y empatiza con los afectados por el 
suceso. Esta situación deviene en una serie de manifestaciones de protesta en contra de lo acaecido que no son desconocidas pero que, sin embargo, ahora cobran una importancia inusual tanto por el número de asistentes como por su simbología.

A medida que va desapareciendo el cadáver del lugar de atentado y es suplantado por otras formas más sutiles de representación, emerge un modelo de representación fotográfica fundamentado en imágenes en contra de la muerte. Fotografías cuyo contenido son concentraciones, minutos de silencio, recogida de firmas para señalar la repulsa a la violencia, pancartas seguidas de numeroso público, interminables colas para visitar la capilla ardiente... copan las páginas de todos los diarios.

La forma de presentar estas acciones, aunque técnicamente más precisas y con una calidad mayor, evoca a los actos funerarios propiamente dichos de finales de los $60 \mathrm{y}$ principios $70 \mathrm{en}$ los que la cantidad de personas insertas en la toma eran el elemento determinante. En la década de los 90, éstas se alternarán con otras en las que se puede identificar a los asistentes al acto de repulsa, pero que no lo muestran en toda la extensión. Las fotografías de la larga cola para visitar la capilla ardiente de Gregorio Ordóñez o la de los miles de donostiarras congregados, más tarde, para repudiar en silencio su asesinato publicadas por Deia el 25 de enero de 1995, son un ejemplo de la primera de las fórmulas.

El 28 de noviembre de 1993 El Correo tras el asesinato de Joseba Goikoetxea insertará dos perspectivas de una manifestación multitudinaria a favor de la Ertzaintza y en contra de la violencia de ETA. En portada se prioriza la longitud y en páginas interiores mediante un acercamiento a un punto concreto prevalece el manifestante.

El asesinato de Miguel Ángel Blanco Villar a causa del contexto en el que tiene lugar, que supuso una dilación en el tiempo debido al secuestro previo, refleja no sólo las pautas de representación que se estaban siguiendo en los últimos años, sino que además asienta los patrones que se seguirán en posteriores atentados. La extensa cobertura informativa durante los días 12 y 13 de julio de 1997 mostrará instantáneas de carteles con la foto de la víctima y textos que aluden a la espera de su retorno, manifestaciones como la de Madrid a la que acuden 50.000 personas en la tarde del viernes o como la del sábado en Bilbao en la que se dan 
cita medio millón de personas, concentraciones en las que los asistentes portan una vela, un lazo azul o las manos pintadas de blanco. Las movilizaciones alcanzan a todos. La Unión Europea, Naciones Unidas, el Papa y cientos de miles de personas anónimas se lanzan a las calles y la prensa así lo capta. Después del asesinato el despliegue informativo, el más extenso en la historia de los atentados de ETA, se mantiene con nuevas tomas de manifestaciones, concentraciones silenciosas y muestras de solidaridad.

A partir de aquí, será en esta nueva situación postmortem que ha ido constituyendo el entorno fotográfico durante esta década donde el spectator encuentre un lugar destacado y quiebre la premisa inicial establecida por Roland Barthes. El que ve sin ser visto se cuela en el encuadre usurpando el papel al espectador instalado durante más de una década en el lugar de los hechos y cuya función en ningún caso estuvo vinculada a la acción mediante las movilizaciones que ahora se registran. Espectador y spectator se funden en una masa anónima que tras observar el "espectáculo" devienen en el concepto de público.

\section{Referencias bibliográficas}

ALONSO ERAUSQUIN, M. (1995): Fotoperiodismo: formas y códigos, Madrid: Ed. Síntesis. BAEZA, P. (2001): Por una función crítica de la fotografía de prensa, Barcelona: Gustavo Gili.

BARTHES, R. (2004): La cámara lúcida, Barcelona: Paidós Comunicación.

BENJAMIN, W. (2007): Sobre la fotografía, Valencia: Pre-textos.

BERGER, J. (1974): Modos de ver, Barcelona: Gustavo Gili.

BERGER, J. (1982): Another way of telling, New York: Panteón Books.

BORDIEU, P. (2003): Un arte medio, Barcelona: Gustavo Gili.

BOSWORTH, P. (1999): Diane Arbus. Una biografía, Barcelona: CIRCE Ediciones, S.A.

BRYSON, N. (1983): Visión y pintura. La lógica de la mirada, Alianza Editorial: Madrid.

COCA, C. (1993): Los medios de comunicación en el País Vasco, Bilbao: Ed. UPV- EHU. 
DEBORD, G. (1999): La sociedad del espectáculo, Editions Gallimard. Pre-textos.

DE DIEGO, E. (1996): “Si nos quedara el cuerpo al menos”, Papel Alpha. Cuadernos de fotografía, $n^{\circ} 1$. Salamanca, Ediciones Universidad de Salamanca.

DUBOIS, P. (1994): El acto fotográfico. De la recepción a la representación, Barcelona: Paidós Comunicación.

DURAND, R. (1995): Le temps de L'image, París: ELA la Différence.

ESPADA, A. (2000): en El País, domingo, 27 de agosto, p.16.

FERNÁNDEZ BAÑUELOS, J.I., (1997): La transición del fotoperiodismo. Un acercamiento a las imágenes de los diarios vizcaínos durante el periodo 1975-1982, Leioa. Tesis doctoral. Universidad del País Vasco.

FONTCUBERTA, J. (1997): El beso de Judas. Fotografía y verdad, Barcelona: Gustavo Gili.

FREUND, G. (1976): La fotografía como documento social, Barcelona: Editorial Gustavo Gili.

GARCIA, Mario R. (1984): Diseño y remodelación de periódicos, Pamplona: Universidad de Navarra.

GONZÁLEZ FLORES, L. (2005): Fotografía y pintura ¿dos medios diferentes? Barcelona: Editorial Gustavo Gili.

KEENE, M. (1995): Práctica de la fotografía de prensa, Barcelona: Ed. Paidós.

LAMBERT, F. (1986): Mytographies, París: Médiathèque-edilig.

LERCHUNDI, A. (1985): La Gaceta del Norte, 83 años de historia, Bilbao: Servicio Editorial Universidad del País Vasco.

PAREJO JIMÉNEZ, N. (2004): Fotografía y muerte: representación gráfica de los atentados de ETA (1968-1997), Bilbao, Servicio Editorial Universidad del País Vasco.

RODRIGO ALSINA, M. (1989): Los modelos de comunicación, Madrid: Tecnos.

RODRÍGUEZ MERCHÁN, E. (1993): La realidad fragmentada. Una propuesta de estudio sobre 
la fotografía y evolución de su uso informativo, Madrid: Editorial de la Universidad Complutense de Madrid.

RUIZ SAN MIGUEL, F. J. (2002): Imagen fija. Fotoperiodismo en la prensa diaria del País Vasco, (1978-1992) Leioa: Servicio Editorial de la Universidad del País Vasco.

SÁNCHEZ TABERNERO, A. (1989): El Correo Español-El Pueblo Vasco y su entorno informativo. 1910-1985, Pamplona: Servicio de Publicaciones de la Universidad de Navarra.

SÁNCHEZ VIGIL, J. M. (1999): El universo de la fotografía, prensa, Madrid: Espasa Calpe.

SCHAEFFER, J. M. (1990): La imagen precaria, Madrid: Ed. Cátedra.

SONTAG, S. (1996): Sobre la fotografía, Barcelona: Edhasa.

SOULAGES, F. (2005): Estética de la fotografía, Argentina: La marca.

VILCHES, L. (1987): Teoría de la imagen periodística, Barcelona: Ediciones Paidós.

WOLLHEIM, R. (1987): La pintura como arte, Washington: Trustees of the Nacional Galery of Art.

V.AA. (2003): Terrorismo, víctimas y medios de comunicación, Madrid: Fundación de Victimas del terrorismo. 